\title{
The ColRS signal transduction system responds to the excess of external zinc, iron, manganese, and cadmium
}

\author{
Kadi Ainsaar, Karl Mumm, Heili Ilves and Rita Hõrak
}

\begin{abstract}
Background: The CoIRS two-component system has been shown to contribute to the membrane functionality and stress tolerance of Pseudomonas putida as well as to the virulence of Pseudomonas aeruginosa and plant pathogenic Xanthomonas species. However, the conditions activating the ColRS pathway and the signal(s) sensed by Cols have remained unknown. Here we aimed to analyze the role of the ColRS system in metal tolerance of $P$. putida and to test whether Cols can respond to metal excess.

Results: We show that the ColRS system is necessary for $P$. putida to tolerate the excess of iron and zinc, and that it also contributes to manganese and cadmium tolerance. Excess of iron, zinc, manganese or cadmium activates ColRS signaling and as a result modifies the expression of ColR-regulated genes. Our data suggest that the genes in the ColR regulon are functionally redundant, as several loci have to be deleted to observe a significant decrease in metal tolerance. Site-directed mutagenesis of ColS revealed that excess of iron and, surprisingly, also zinc are sensed by a conserved ExxE motif in ColS's periplasmic domain. While ColS is able to sense different metals, it still discriminates between the two oxidation states of iron, specifically responding to ferric and not ferrous iron. We propose a signal perception model involving a dimeric ColS, where each monomer donates one ExxE motif for metal binding.
\end{abstract}

Conclusions: Several transition metals are essential for living organisms in certain amounts, but toxic in excess. We show that ColRS is a sensor system which detects and responds to the excess of physiologically important metals such as zinc, iron and manganese. Thus, the ColRS system is an important factor for metal homeostasis and tolerance in P. putida.

Keywords: ColRS two-component system, Metal tolerance, Histidine kinase, Signal perception, Pseudomonas putida

\section{Background}

Metal ions are important catalytic and structural cofactors of proteins and are therefore necessary for the survival of all organisms. Among the metals found in enzymes, magnesium is the most abundant, followed by the transition metals zinc, iron and manganese. Other transition metals, such as cobalt, copper and nickel are less frequent in enzymes [1], but still important in a variety of cellular processes.

Although transition metals play a vital role in bacterial physiology, their excess can be toxic. For instance, iron can catalyze the formation of toxic reactive oxygen species via the Fenton reaction, which results in oxidative

\footnotetext{
* Correspondence: rita.horak@ut.ee

Institute of Molecular and Cell Biology, University of Tartu, 51010 Tartu,
} Estonia

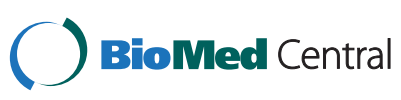

damage of proteins, lipids and DNA [2,3]. Highly competitive zinc and copper can easily outcompete other metals from metalloproteins [4] and therefore their free cytosolic concentrations are kept low [5,6]. To protect the cell from metal toxicity, bacteria most commonly use active metal efflux [7-9], but also metal chelation by specific proteins such as ferritin and metallothionein $[10,11]$. These processes, alongside with the repression of metal uptake systems, help maintain metal homeostasis in the condition of metal excess.

Given that maintenance of metal homeostasis is essential for bacteria, it is not surprising that they possess many regulatory pathways for sensing both the extraand intracellular concentrations of metals. The cytosolic metal levels are monitored by different metalloregulators, such as Fur (for iron), Zur (for zinc), MntR (for manganese), etc., which control the expression of high- 
affinity metal uptake pathways that are able to supply the cell with the limiting metal [12-14]. Moreover, these systems also regulate the genes necessary for the detoxification of excess metals [15]. The external metal levels are detected primarily by transmembrane sensor proteins that belong to two-component signal transduction pathways. These sensors mediate the regulation of metal homeostasis via their cognate cytoplasmic response regulators. For instance, the PmrA-PmrB system in Salmonella monitors the amount of extracellular $\mathrm{Fe}^{3+}$ and $\mathrm{Al}^{3+}$ ions [16] and its activation leads to several lipopolysaccharide modifications [17], which alleviate metal toxicity by decreasing $\mathrm{Fe}^{3+}$ binding to the cell surface $[18,19]$. The PmrA-PmrB ortholog in E. coli, the BasS-BasR system, reacts to iron and zinc and regulates genes involved in membrane functions and stress response [20]. The ZraSR two-component system responds to high periplasmic $\mathrm{Zn}^{2+}$ and $\mathrm{Pb}^{2+}$ concentrations by up-regulating the expression of the periplasmic zinctrapping chaperone ZraP, yet the role of this signal pathway in zinc resistance remains ambiguous [21,22]. These examples demonstrate that although some metal sensor systems can detect more than one metal, they are generally remarkably metal-specific, highlighting also the need for a large amount of sensor systems to maintain cellular metal homeostasis.

The genus Pseudomonas includes a great variety of widely distributed species that are known for their metabolic versatility and remarkable environmental adaptability [23]. Many pseudomonads are intrinsically highly resistant to different toxic compounds such as antibiotics, aromatics, detergents and heavy metals [24], which can be explained not only by their low outer membrane permeability and the presence of multiple efflux systems, but also by the large number of two-component signaling systems that are potentially able to shape the bacterial response to external stressors [25]. Interestingly, only a few metal resistance-regulating two-component systems have been characterized in pseudomonads so far. CzcRS has been described as a zinc-responsive system conferring resistance to zinc, cadmium and cobalt, but also to the antibiotic imipenem [26]. CopRS is a copperactivated signal system, which is required for copper resistance in P. aeruginosa [27], but also contributes to zinc resistance by activating the $c z c R S$ operon [28]. Contrarily, the CopRS ortholog of P. fluorescens seems to behave as a copper deficiency sensor that activates copper uptake when necessary [29]. This illustrates that even highly related sensor systems may sense and respond to different stimuli. Another example of that kind is PmrAB, which responds to external iron and alleviates iron toxicity in Salmonella enterica [16,18], but its ortholog in P. aeruginosa is not involved in iron resistance [30].
One of the well-conserved two-component systems in pseudomonads is the ColRS signaling pathway [31]. Its orthologs are also present in other environmental bacteria but seem to be absent from enteric bacteria. The ColRS system was first described as a root colonization factor of $P$. fluorescens [32]. Recent reports indicate that ColRS signaling is also important for the virulence of P. aeruginosa [33] and plant pathogenic Xanthomonas species [34,35]. ColRS deficiency results in pleiotropic effects in $P$. putida, including lowered phenol tolerance $[36,37]$ and subpopulation lysis when bacteria grow under glucose limitation [38,39]. The phenotypic effects of ColRS deficiency as well as the identified target genes of the regulator ColR suggest that the ColRS system is involved in the regulation of membrane functionality $[34,36,38,40,41]$. However, so far the molecular basis of the membrane stress of the colR mutant as well as the signal sensed by $\mathrm{ColS}$ has remained unclear. Interestingly, recent reports suggest that the ColRS system may be involved in metal homeostasis, as it contributes to the copper tolerance of $X$. citri [34], cadmium tolerance of $X$. campestris [42] and multi-metal resistance of $P$. putida CD2 [43]. However, as the P. putida CD2 is a strain that is intrinsically highly resistant to different metal ions, the results cannot be easily extrapolated to other pseudomonads and the putative role of the ColRS system in metal resistance is yet to be determined.

Here we aimed to evaluate the impact of the ColRS system on metal tolerance of $P$. putida and to test whether metal excess could generate the activating signal for the sensor system. We demonstrate that ColRS signaling significantly contributes to $P$. putida's zinc and iron tolerance, but is also slightly important in manganese and cadmium tolerance. All four of these metals can trigger ColS signaling, resulting in activation of the ColR regulon. We present evidence that a conserved ExxE motif in the periplasmic domain of ColS is required for sensing both zinc and iron, whereas only ferric and not ferrous iron can act as the signal for ColS.

\section{Results}

The ColRS system is required for growth in the excess of zinc, iron, manganese and cadmium

To test whether the ColRS system is involved in metal resistance, we determined the MIC values of different transition metals for wild-type $P$. putida PaW85 and for its colR- and colS-deficient derivatives. In the liquid LB medium, the colR and cols mutants showed clearly increased sensitivity to zinc and iron compared to the parent strain (Table 1). The mutant strains were also slightly more sensitive to $\mathrm{Mn}^{2+}$ and $\mathrm{Cd}^{2+}$ but their resistance to $\mathrm{Co}^{2+}, \mathrm{Cu}^{2+}$ and $\mathrm{Ni}^{2+}$ resembled that of wild-type (Table 1 ). With the exception of $\mathrm{Cd}^{2+}$, similar results were observed when metal resistance was analyzed on LB solid medium - 
Table 1 MICs of different metals for $P$. putida parent strain PaW85 (wt) and its colR and cols knockouts ${ }^{\mathrm{a}}$

\begin{tabular}{lccccccc}
\hline & $\mathbf{Z n S O}_{\mathbf{4}}$ & $\mathrm{FeSO}_{\mathbf{4}}$ & $\mathrm{CuSO}_{\mathbf{4}}$ & $\mathbf{C d S O}_{\mathbf{4}}$ & $\mathbf{C o C l}_{\mathbf{2}}$ & $\mathbf{M n C l}_{\mathbf{2}}$ & $\mathbf{N i S O}_{\mathbf{4}}$ \\
\hline wt & 5 & 5 & 6 & 1.5 & 1 & 8 & 3 \\
colR & 2 & 1.25 & 6 & 1 & 1 & 6 & 3 \\
cols & 2 & 1.25 & 6 & 1 & 1 & 6 & 3 \\
\hline
\end{tabular}

${ }^{\mathrm{a}}$ Numbers indicate millimolar concentrations.

the growth of the colR and cols mutants was highly sensitive to the excess of zinc and iron, considerably impaired by manganese, but was not affected by other tested metals (Figure 1). Complementation of the colsand colR-deficient strains with an extra copy of colS or colR genes under the control of the tac promoter and LacI repressor enabled normal growth of mutant bacteria under the condition of metal excess (Figure 1). The finding that the metal resistance of the RtacR strain was already restored without induction of colR expression with IPTG is in good correlation with previous results, as the $l a c I^{q}-P_{\text {tac }}$-colR expression cassette has been shown to be highly leaky in $P$. putida [44]. In order to test whether the signal transduction between ColS and ColR is important for metal resistance, the colR mutant was complemented with $\mathrm{ColR}_{\mathrm{D} 51 \mathrm{~A}}$, a phosphorylation-deficient variant of ColR [44]. As expression of ColR $\mathrm{D}_{\mathrm{D} 1 \mathrm{~A}}$ could not alleviate the metal sensitivity of the colR mutant (Figure 1), the signal transduction between ColS and ColR is clearly necessary for the growth of $P$. putida in high concentrations of zinc, iron and manganese.

Genes of the ColR regulon respond to the excess of zinc in a ColS- and ColR-dependent manner

Previous studies have identified several ColR-regulated genes in $P$. putida $[36,40]$. However, considering the quite modest effect of ColR in the regulation of those genes, it was proposed that the ColS-activating signal was not present under the conditions applied [40]. To test the hypothesis that metal excess could generate the activating signal for the ColS-ColR system, we investigated the expression of the ColR regulon genes under the conditions of high $\mathrm{Zn}^{2+}$. Analysis of known ColR-responsive promoters in wild-type $P$. putida revealed clear zincpromoted induction of ColR-activated promoters (PP0035, PP0900, PP0903, PP1636) and inhibition of ColR-repressed ones (PP0268, PP0737) (Figure 2). Comparison of promoter activities of wild-type bacteria grown in the presence of either 0.6 or $1.7 \mathrm{mM} \mathrm{ZnSO}_{4}$ shows that zinc affects the ColR-regulated promoters in a concentration-dependent manner, resulting in a higher response at $1.7 \mathrm{mM}$ $\mathrm{ZnSO}_{4}$ (Figure 2). The transcriptional effect of zinc clearly depended on the functionality of ColR and ColS because the zinc-responsiveness of promoters was not observed in colR- and colS-deficient strains (Figure 2). Only the PP0035 promoter displayed partial zinc-promoted but ColR-independent activation. Note that due to the high zinc-sensitivity of the colR and colS mutants, the promoter analysis in these strains was only possible in the presence of $0.6 \mathrm{mM}$ but not $1.7 \mathrm{mM} \mathrm{ZnSO}_{4}$. In addition to promoters that were previously identified as ColR-regulated, we also studied whether some predicted members of the ColR regulon [40] could respond to zinc. Transcriptional analysis of several putative ColR target genes identified two new ColR-activated genes, PP2579 and PP5152, which responded to zinc in a ColR- and ColS-dependent manner (Figure 2). PP2579 and PP5152 code for two putative inner membrane proteins, the phosphoethanolamine transferase CptA and a conserved hypothetical protein, respectively, supporting the previously proposed role of the ColRS system in the regulation of membrane functionality. Together,

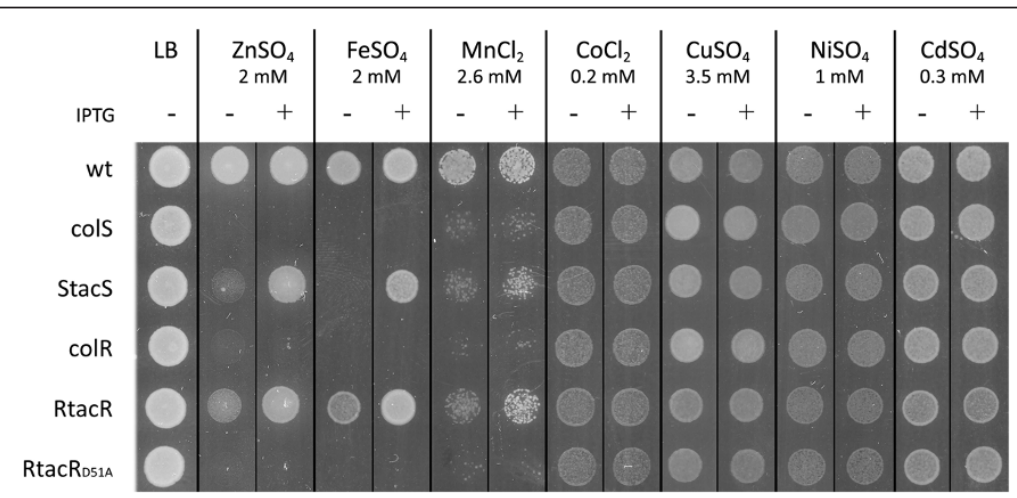

Figure 1 Metal tolerances of different $P$. putida strains. P. putida wild-type strain PaW85 (wt), the colS-deficient strain (colS), colS-deficient strain complemented with the cols gene under the control of the inducible $P_{\text {tac }}$ promoter (StacS), colR-deficient strain (colR), colR-deficient strain complemented with the colR gene under the control of the inducible $P_{\text {tac }}$ promoter (RtacR) and colR-deficient strain complemented with the D51A mutant colR gene under the control of the inducible $P_{\text {tac }}$ promoter ( $\left(\operatorname{tac}_{\mathrm{D} 51 \mathrm{~A}}\right.$ ) were grown on solid LB medium containing different metal salts for 20 hours at $30^{\circ} \mathrm{C}$. ColS and ColR expression was induced with $0.5 \mathrm{mM} \mathrm{IPTG} \mathrm{indicated} \mathrm{by} \mathrm{"}+$ ". Approximately 5000 cells were inoculated per spot. 


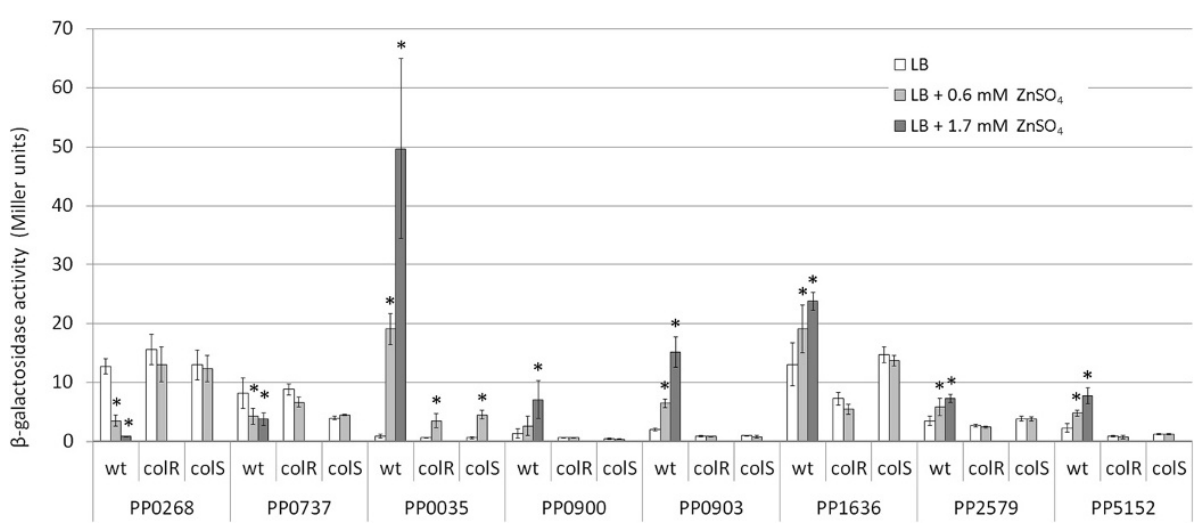

Figure 2 ColR-regulated genes respond to excess of zinc. $\beta$-galactosidase activities measured in $P$. putida wild-type (wt), colR-and colS-deficient strains (colR and colS, respectively) carrying the transcriptional fusions of PP0268, PP0737, PP0035, PP0900, PP0903, PP1636, PP2579 or PP5152 promoters with lacZ in the plasmid p9T BlacZ. P. putida wild-type was grown in LB medium or LB where $0.6 \mathrm{mM}$ or $1.7 \mathrm{mM}_{\mathrm{ZnSO}}$ was added. colR- and colS-deficient strains were grown in LB or LB supplemented with $0.6 \mathrm{mM} \mathrm{ZnSO}_{4}$. Data (means with $95 \%$ confidence intervals) of at least three independent experiments are presented. Asterisks indicate statistically significant differences $(p<0.05$, two-way ANOVA with post-hoc Tukey's Unequal N HSD test) between values obtained in LB and in LB supplemented with $\mathrm{ZnSO}_{4}$.

our data indicate that ColRS signaling is activated by the excess of zinc, resulting in an altered expression of the ColR regulon genes.

\section{The excess of iron, manganese and cadmium can also affect the expression of the ColR regulon}

Data presented above show that besides being important in zinc resistance, the ColRS system is also required for iron, manganese and cadmium resistance. To analyze whether other transition metals besides zinc can activate ColRS signaling, one ColR-activated (PP0903) and one ColR-repressed (PP0268) promoter was tested for metal responsiveness. The highest concentration of each metal tolerable to the cols mutant without growth retardation was used in this assay. Both ColR-regulated promoters respond to the excess of iron, manganese and cadmium, although the degree of response differs between different metals (Figure 3). To control whether iron-, manganeseand cadmium-promoted regulation of PP0903 and PP0268 indeed depends on ColRS activation, the promoters were also tested in the colS-deficient background. As the absence of ColS abolished the response of the promoters to metals (Figure 3), we conclude that four transition metals - zinc, iron, manganese and cadmium - can

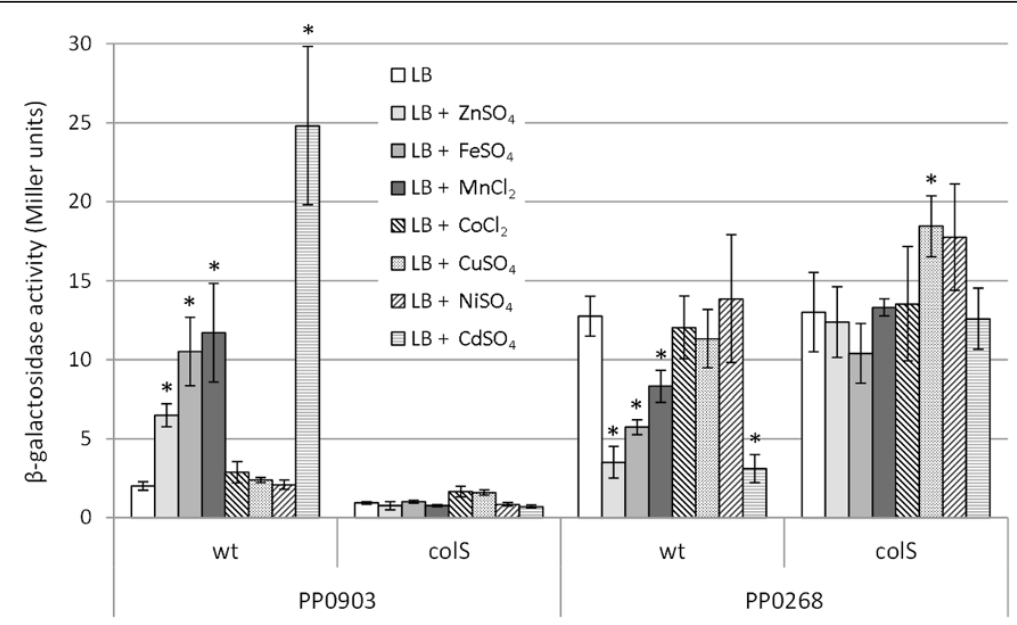

Figure 3 ColR-regulated genes respond to excess of zinc, iron, manganese and cadmium. $\beta$-galactosidase activities measured in $P$. putida wild-type (wt) and colS-deficient strain (colS) carrying the transcriptional fusions of PP0268 or PP0903 promoters with lacZ in the plasmid p9TT 1 lacZ. Bacteria were grown in $\mathrm{LB}$ medium and in $\mathrm{LB}$ containing either $0.6 \mathrm{mM} \mathrm{ZnSO}_{4}, 0.15 \mathrm{mM} \mathrm{FeSO}_{4}, 0.5 \mathrm{mM} \mathrm{MnCl}_{2}, 0.1 \mathrm{mM} \mathrm{CoCl}_{2}, 2 \mathrm{mM} \mathrm{CuSO}_{4}, 0.5 \mathrm{mM}$ $\mathrm{NiSO}_{4}$ or $0.2 \mathrm{mM} \mathrm{CdSO}_{4}$. Data (means with $95 \%$ confidence intervals) of at least three independent experiments are presented. Asterisks indicate statistically significant differences ( $p<0.05$, two-way ANOVA with post-hoc Tukey's Unequal N HSD test) between values obtained in LB and in LB supplemented with metal salt. 
activate the ColRS signal transduction pathway. In accordance with $\mathrm{MIC}$ measurements, $\mathrm{Co}^{2+}, \mathrm{Cu}^{2+}$ and $\mathrm{Ni}^{2+}$ did not influence transcription from the ColR regulon genes, indicating that these metals do not produce the signal for the ColRS system.

\section{The expression of the colRS operon itself is not responsive to metal excess}

As genes of two-component systems involved in metal homeostasis are often induced in response to metal excess $[26,45,46]$, we asked whether this could be the case with colRS as well. Previous studies have shown that despite being preceded by a ColR binding site, the colR promoter is not autoregulated and this site is associated only with the regulation of PP0900, located upstream of colR [40]. However, as this data was obtained under non-inducing conditions, we tested whether the expression of the colRS operon may respond to metal excess. Measurement of the $\beta$-galactosidase activity originated from the colR-lac $Z$ transcriptional fusion showed that the colR promoter is influenced neither by $0.6 \mathrm{mM}$ zinc nor by $0.15 \mathrm{mM}$ iron (Figure $4 \mathrm{~A}$ ). Western blot analysis with anti-ColR antibodies confirmed that the abundance of ColR is not affected by the external excess of zinc or iron (Figure 4B).

\section{Impact of the ColR regulon genes on the zinc and iron resistance is highly redundant}

As colRS-deficiency leads to sensitivity to several transition metals and these metals modulate the expression of the ColR regulon, we reasoned that the ColR-regulated genes should be important for metal resistance. To identify genes involved in metal resistance, we determined the MICs of metals for a set of knockouts of ColR regulon genes. We presumed that inactivation of the ColRactivated genes in wild-type background will decrease the metal resistance of bacteria and, vice versa, disruption of ColR-repressed genes will increase the metal resistance of the colR-deficient strain. Surprisingly, single gene or operon knockouts in the wild-type P. putida revealed no effect on iron (Table 2), manganese and cadmium (data not shown) resistance. The zinc resistance of these strains was also unaffected, except for a strain devoid of the PP0035-33 operon, which displayed a slightly lower MIC of zinc than the wild-type (Table 2). Furthermore, the disruption of ColR-repressed PP0268 and PP0737 in the colR-deficient strain did not influence the metal resistance of the colR mutant, either. In order to test whether the ColR regulon genes display functional redundancy, we constructed a set of strains devoid of several ColR-regulated genes and operons. Analysis of these mutants for metal susceptibility revealed that absence of at least four ColR-activated loci (PP0035-33, PP0900, PP0903-905, PP2579) was necessary to observe

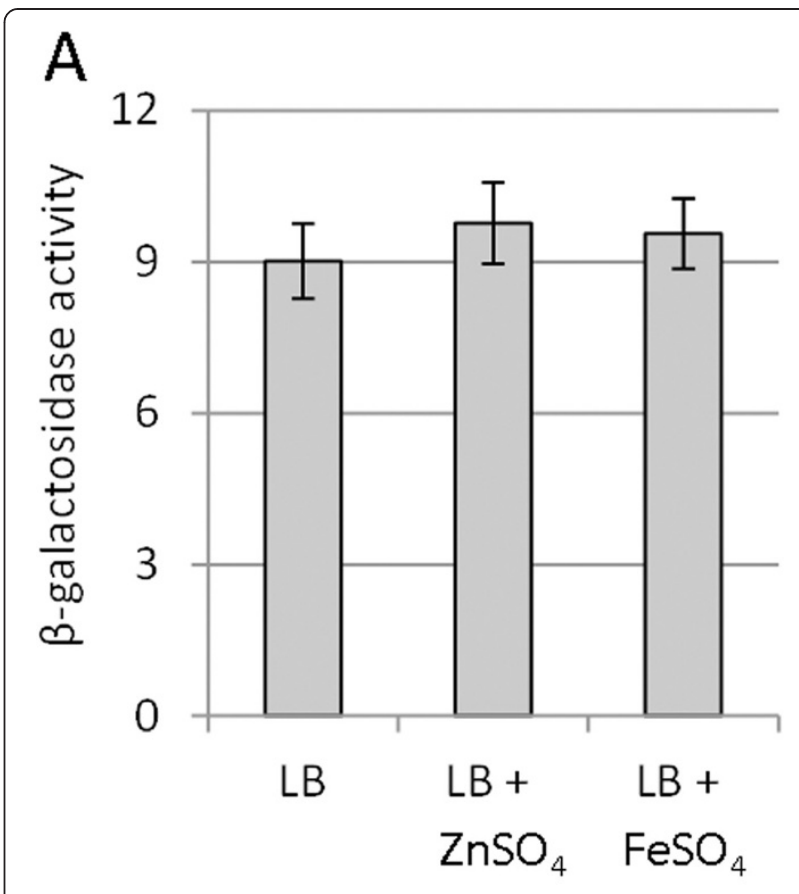

B
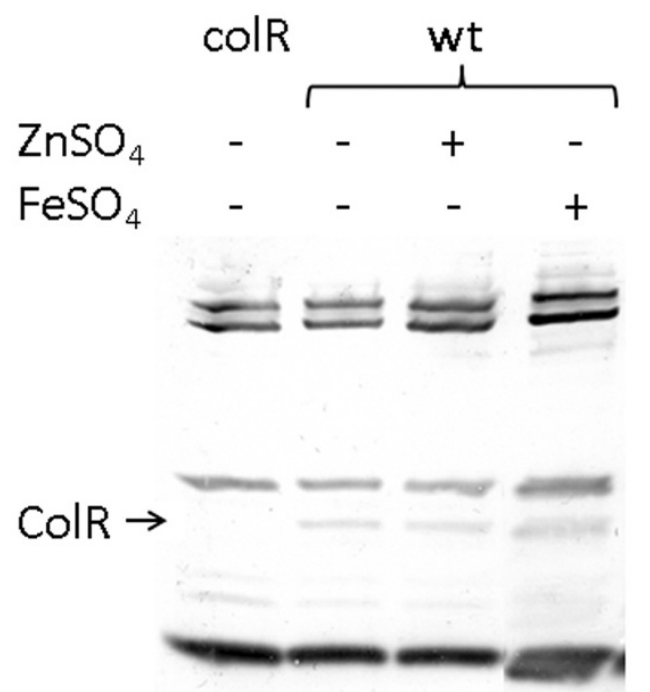

Figure 4 Expression of ColR is not induced by metal stress. (A) $\beta$-galactosidase activities measured in P. putida wild-type PaW85 strain carrying the transcriptional fusion of the colRS operon promoter with lacZ in the plasmid p9TT 1 lacZ. Bacteria were grown in LB medium and in $\mathrm{LB}$ containing $0.6 \mathrm{mM} \mathrm{ZnSO}_{4}$ or $0.15 \mathrm{mM} \mathrm{FeSO}_{4}$. Data (means with $95 \%$ confidence intervals) of at least four independent experiments are presented. (B) Western blot showing ColR expression in P. putida wild-type (wt) and colR-deficient strain (colR). Location of ColR is indicated with an arrow. Proteins were extracted from bacteria grown in LB medium and in LB containing $0.6 \mathrm{mM} \mathrm{ZnSO}_{4}$ or $0.15 \mathrm{mM}$ $\mathrm{FeSO}_{4}$. All lanes contain $3 \mu \mathrm{g}$ of total protein extract.

a significant decrease in the iron tolerance of $P$. putida (Table 2). As the iron tolerance of single, double and triple mutants was not changed, the reduced iron resistance of the quadruple mutant cannot be attributed to 
Table 2 MICs of zinc and iron for $P$. putida parent strain PaW85 (wt) and different knockout strains

\begin{tabular}{llcc}
\hline $\begin{array}{l}\text { Disrupted or } \\
\text { deleted locus }\end{array}$ & (product, putative function) & $\begin{array}{c}\mathrm{ZnSO}_{4} \\
\mathbf{m M}\end{array}$ & $\begin{array}{c}\mathrm{FeSO}_{\mathbf{4}} \\
\mathbf{m M}\end{array}$ \\
\hline Wt & & 5 & 5 \\
colR & & 2 & 1.25 \\
PP0035-PP0033 & (LPS synthesis and modification) & 4 & 5 \\
PP0268 & (porin OprE3) & 5 & 5 \\
PP0737 & (PagL, LPS modification) & 5 & 5 \\
PP0900 & (phospholipide metabolism) & 5 & 5 \\
PP0903-PP0905 & (LPS modification) & 5 & 5 \\
PP1636 & (DgkA, phospholipide metabolism) & 5 & 5 \\
PP2579 & (CptA, LPS modification) & 5 & 5 \\
PP5152 & (hypothetical protein) & 5 & 5 \\
PP0035-PP0033, PP0900 & 4 & 5 \\
PP0035-PP0033, PP0903-PP0905 & 5 & 5 \\
PP0035-PP0033, PP2579 & 4 & 5 \\
PP0903-PP0905, PP2579 & 4 & 5 \\
PP0035-PP0033, PP2579, PP0903-PP0905 & 4 & 5 \\
PP0035-PP0033, PP2579, PP0903-PP0905, PP0900 & 3.5 & 3 \\
PP0035-PP0033, PP2579, PP0903-PP0905, PP5152 & 4 & 5 \\
colR, PP0268 & & 2 & 1.25 \\
colR, PP0737 & & 2 & 1.25 \\
\hline
\end{tabular}

one particular locus and it rather indicates concert action of the ColR regulon genes. Analysis of zinc tolerance of strains devoid of multiple ColR-regulated genes showed that all strains lacking the PP0035-33 operon are slightly more sensitive to zinc, but no clear effect of other genes, with the exception of PP0900, could be recorded (Table 2). The detected MICs of all the strains for cadmium and manganese were similar to wild-type, indicating that none of the tested ColR regulon genes can significantly influence the tolerance of $P$. putida to these metals (data not shown). Importantly, even though some mutant strains displayed lower MIC values of iron and zinc compared to wild-type, none of them was as impaired as the colR-deficient strain. This can be explained by the weak effect of any single ColR-regulated locus on metal tolerance, but it may also indicate that the ColR regulon identified so far is yet incomplete.

\section{ColS possesses a putative iron binding motif in its periplasmic domain}

ColS is a canonical membrane kinase with two transmembrane domains connected by a 96 amino acid periplasmic loop, which is most probably involved in signal recognition (Figure 5A). Metal-sensing sites of proteins are composed of several metal-binding residues, which are most often glutamic acid, aspartic acid and histidine [47].
To predict the periplasmic amino acids that are putatively involved in metal sensing by ColS, we aligned the periplasmic regions of 47 annotated ColS orthologs represented in the Pseudomonas database [31]. From 96 putative periplasmic residues, 14 turned out to be conserved among all analyzed ColS proteins and four of these identical residues were glutamic acids in positions 38, 96, 126 and 129 (Figure 5 B and C). Notably, E126 and E129 appeared in the most conserved FExRE sequence, which resembles the EXXE motif implicated in direct binding of iron in several proteins $[16,48,49]$. Thus, we hypothesized that this motif may bind iron in ColS. Considering that the ColRS system also responds to zinc and that histidine is a particularly important residue in coordination of $\mathrm{Zn}^{2+}$ in several zinc-binding proteins [12], we also analyzed the conservation of five periplasmic His residues found in ColS of $P$. putida. The most conserved histidine, $\mathrm{H} 35$, was present in 44 out of $47 \mathrm{ColS}$ proteins (Figure 5B). If the eight less conserved ColS orthologs were omitted from the alignment, then also H95 and H105 appeared to be conserved.

\section{Conserved glutamic acids of the ExxE motif in ColS are necessary for metal-promoted activation of a ColR-regulated promoter}

To examine the role of the conserved glutamic acids and histidines in the signaling ability of ColS, the ColS variants possessing a substitution mutation (H35A, E38Q, H95A, E96Q, H105A, E126Q or E129Q) in the periplasmic domain were cloned under the control of the tac promoter. We also constructed a ColS derivative carrying the replacement of aspartic acid at position 57 (D57N) as well as ColS with both E126Q and E129Q replacements. The expression cassettes for the mutant ColS variants were introduced into the chromosome of the colS-deficient strain and the abundance of the overexpressed ColS proteins was analyzed with anti-ColS antibodies. However, due to the low sensitivity of antibodies we could detect neither the wild-type nor the overexpressed level of ColS (data not shown). Thus, the abundance of ColS in P. putida seems to be low, even when expressed from the IPTG-inducible tac promoter.

Analysis of metal-promoted activation of ColR-regulated PP0903 revealed that responsiveness of ColS to both iron and zinc was lost when either of two conserved glutamates in the FEERE motif were mutated (Figure 6). Bacteria expressing single mutants $\mathrm{ColS}_{\mathrm{E} 126 \mathrm{Q}}$ and $\mathrm{ColS}_{\mathrm{E} 129 \mathrm{Q}}$ as well as the double mutant $\mathrm{ColS}_{\mathrm{E} 126 \mathrm{Q} / \mathrm{E} 129 \mathrm{Q}}$ displayed a basal expression level of PP0903 promoter, which was comparable to the non-induced controls when either IPTG or metal was absent from medium (Figure 6, data for LB + $0.6 \mathrm{mM}$ $\mathrm{ZnSO}_{4}$ are not shown). None of the other amino acid substitutions could decrease the signaling ability of $\mathrm{ColS}$. Quite the contrary, some ColS mutants $\left(\mathrm{ColS}_{\mathrm{H} 35 \mathrm{~A}}\right.$, 


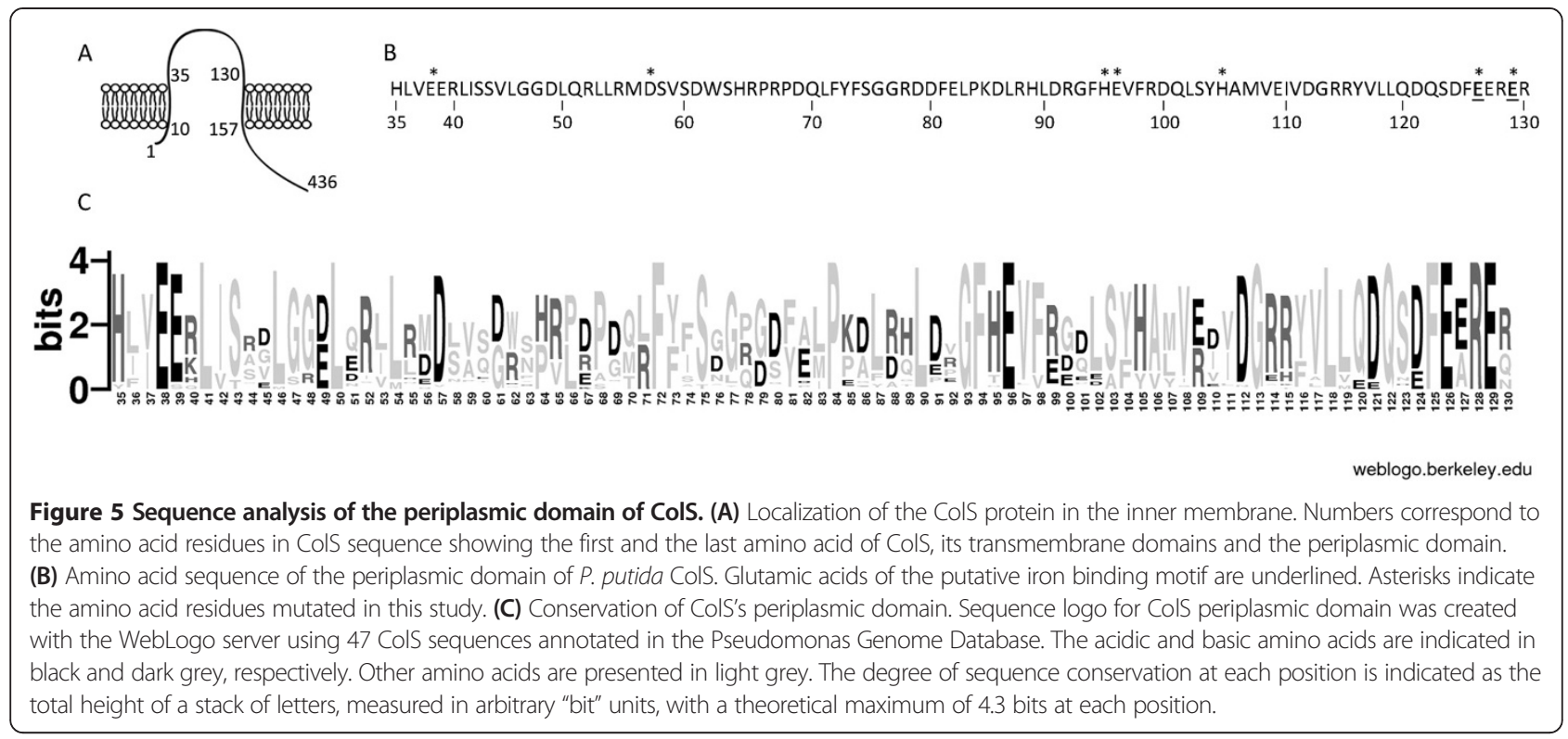

$\mathrm{ColS}_{\mathrm{E} 38 \mathrm{Q}}, \mathrm{ColS}_{\mathrm{D} 57 \mathrm{~N}}$, and $\left.\mathrm{ColS}_{\mathrm{H} 105 \mathrm{~A}}\right)$ demonstrated an even higher responsiveness to both zinc and iron than wildtype ColS. Interestingly, analysis of $\mathrm{ColS}_{\mathrm{E} 38 \mathrm{Q}}, \mathrm{ColS}_{\mathrm{D} 57 \mathrm{~N}}$, and $\mathrm{ColS}_{\mathrm{H} 105 \mathrm{~A}}$ mutants in the medium which was supplemented with IPTG but not with metals (Figure 6) revealed partial activation of the PP0903 promoter. These data indicate that the FEERE motif is implicated in signal perception, but also suggest that amino acids H35, E38, D57 and H105 regulate the metal-sensing ability of ColS. The alternative explanation for the signal-blind phenotype of some of the mutant ColS proteins could be their lower stability. However, we do not believe that a single amino acid substitution in the periplasmic domain of a membrane protein can essentially affect its stability as there are several indications that membrane proteins are remarkably tolerant to substitution mutagenesis [50,51].

\section{ColS specifically responds to ferric iron}

To our knowledge, there are three bacterial two-component systems, PmrA/PmrB, FirR/FirS, and BqsR/BqsS, which can sense extracellular iron $[16,46,52]$. All of these signaling systems can discriminate between ferrous $\left(\mathrm{Fe}^{2+}\right)$ and ferric $\left(\mathrm{Fe}^{3+}\right)$ ions. While PmrB of Salmonella enterica specifically responds to $\mathrm{Fe}^{3+}[16]$, BqsS of Pseudomonas aeruginosa and FirS of Haemophilus influenzae are activated by $\mathrm{Fe}^{2+}$ only $[46,52]$. In all the experiments

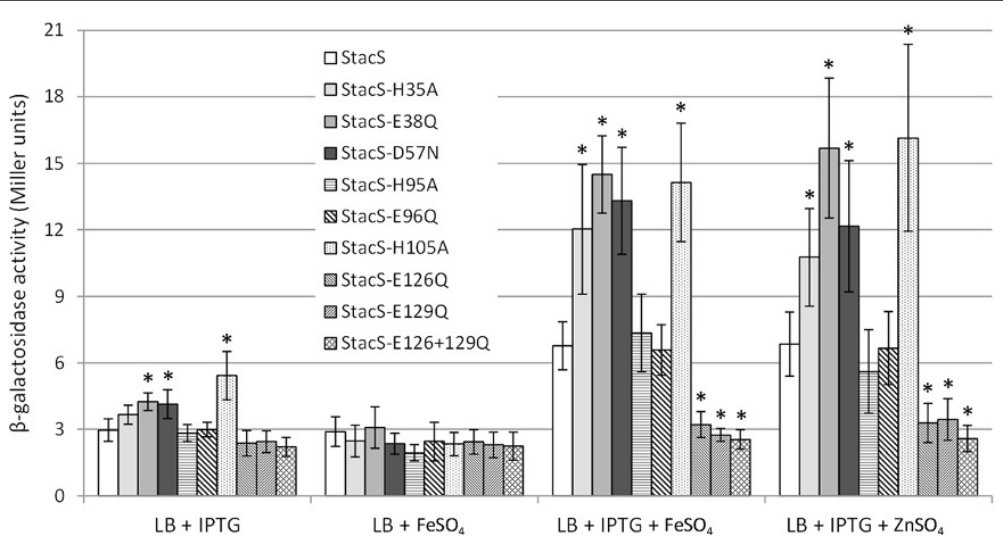

Figure 6 Conserved glutamic acids of the ExxE motif in ColS are necessary for metal-promoted activation of a ColR-regulated promoter. $\beta$-galactosidase activities measured in P. putida colS-deficient strain complemented with either the wild-type colS (StacS) or the colS variants carrying single substitutions of H35A, E38Q, D57N, H95A, E96Q, H105A, E126Q, E129Q or the double substitutions of E126Q and E129Q under the control of the inducible $\mathrm{P}_{\text {tac }}$ promoter. All strains carry the transcriptional fusion of the PP0903 promoter with lacZ in the plasmid p9TT 1 lac $Z$. Bacteria were grown in LB medium containing $0.1 \mathrm{mM}$ IPTG or $0.15 \mathrm{mM} \mathrm{FeSO}_{4}$ or $0.1 \mathrm{mM}$ IPTG and $0.15 \mathrm{mM} \mathrm{FeSO}_{4}$ or $0.1 \mathrm{mM}$ IPTG and $0.6 \mathrm{mM} \mathrm{ZnSO}$. Data (means with 95\% confidence intervals) of at least six independent experiments are presented. Asterisks indicate a statistically significant difference ( $p<0.01$, Student's $t$-test) between the StacS strain and a strain carrying a mutant ColS in a particular medium. 
presented above we used ferrous sulphate $\left(\mathrm{FeSO}_{4}\right)$ as the source of iron, however, the ferrous ions are easily oxidized to ferric ions in the solutions. In order to discriminate whether $\mathrm{Fe}^{2+}$ or $\mathrm{Fe}^{3+}$ can activate ColS, the metal-promoted activation of the PP0903 promoter was tested in media supplemented either with ferrous or ferric sulphate. To keep iron in a reduced state we also performed experiments in the presence of $5 \mathrm{mM}$ sodium ascorbate. Data in Figure 7 show that transcription from the PP0903 promoter can be induced both by ferrous and ferric sulphate. However, considering that sodium ascorbate can suppress the responses elicited by either metal salt, we deduce that ferric iron is the signal sensed by ColS. This conclusion was further supported by the finding that the same amount of sodium ascorbate could not affect the zinc-promoted activation of ColS (data not shown).

\section{Discussion}

The controversial nature of biologically important transition metals requires constant monitoring of their concentrations to avoid potential toxic effects of metals. In this study, we demonstrate that the ColRS two-component

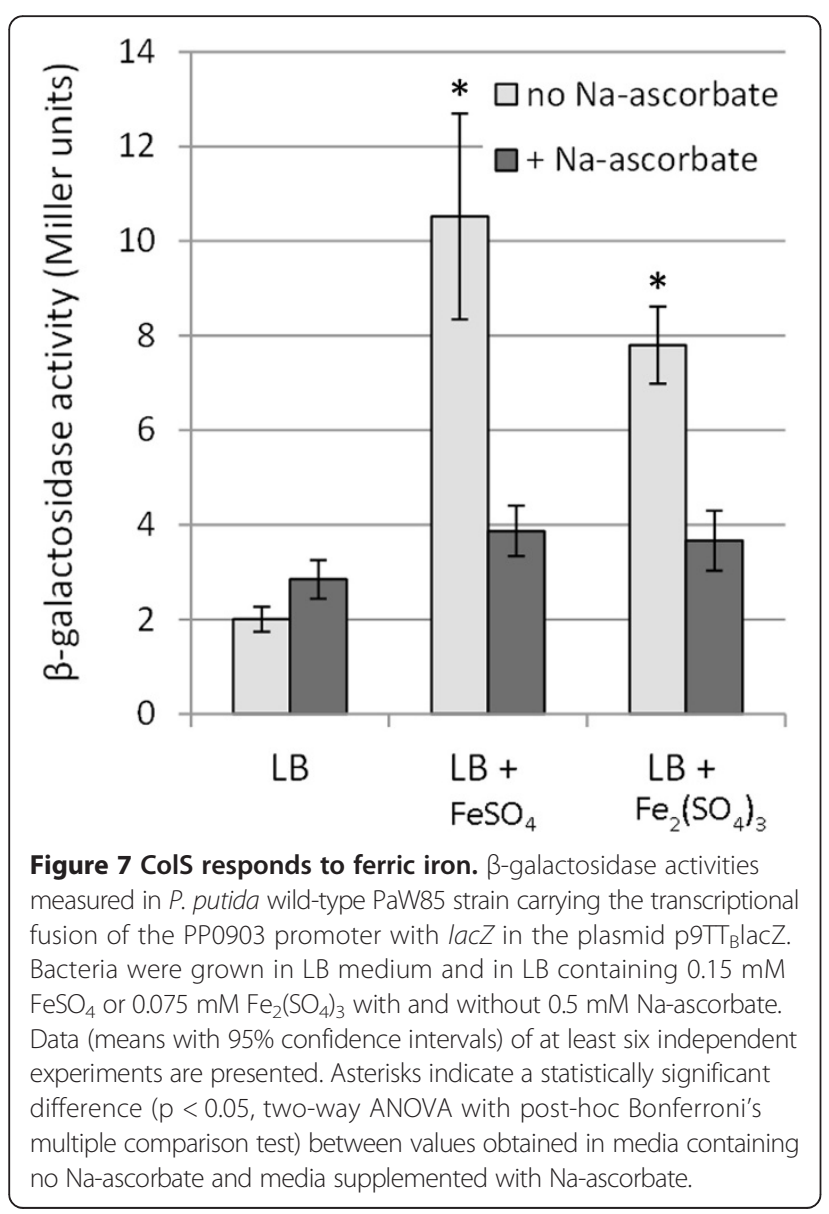

system acts as a sentinel for external levels of zinc, iron, manganese, and cadmium. Metal-promoted signaling of ColRS system results in the activation of the ColR regulon, which contributes to metal tolerance of $P$. putida.

The finding that the ColRS system is involved in metal tolerance is consistent with previous reports as the ColRS system has been shown to promote heavy metal tolerance of $P$. putida CD2 [43], cadmium tolerance of Xanthomonas campestris [42], and copper tolerance of $X$. citri [34]. Comparison of our metal tolerance data for P. putida PaW85 with those previously published for P. putida CD2 [43] revealed that the absence of the ColRS system results in different outcomes in these two strains. While the disruption of ColRS signaling in $P$. putida PaW85 increases the sensitivity of bacteria only to the excess of zinc, iron, manganese and cadmium, the ColRS-deficient $P$. putida CD2 also displays higher susceptibility to copper, cobalt and nickel. However, one should consider that $P$. putida CD2 was isolated from sewage sludge as a cadmiumresistant bacterium [43] and this strain is substantially more tolerant to metals than P. putida PaW85. Therefore, it is not surprising that these two P. putida strains behave somewhat differently from each other although their colRS operons are almost identical. The ColRS systems of $X$. campestris and $X$. citri are distantly related orthologs of the ColRS of $P$. putida, as judged by the $57 \%$ identity of ColR and only about $26-27 \%$ identity of ColS proteins. Furthermore, while the C-terminal kinase domains of the ColS proteins of $P$. putida and Xanthomonas strains are considerably similar, the $\mathrm{N}$-terminal sensing domains are remarkably divergent (not shown). This suggests that the signal recognition mechanism of ColS in Xanthomonas may be different from that in P. putida.

The ColR regulon genes responded to the physiologically important zinc, iron and manganese, but also to the dispensable and highly toxic cadmium. The ColRS-dependent response to the excess of zinc and iron is obviously highly relevant because disruption of the ColRS system remarkably decreased both the iron and zinc tolerance of $P$. putida (Table 1). We also showed that the functionality of the ColR regulon is important in iron and zinc tolerance, although the impact of any single gene alone is weak and the regulon genes appear to act redundantly (Table 2 ). Differently from zinc and iron, the MICs of manganese and cadmium for the ColRS-deficient strain were only slightly lower than that of the wild-type, suggesting that the activation of the ColR regulon by these metals is not as important for P. putida as the response induced by zinc or iron. However, manganese is considered less harmful than zinc or iron as it is less able to replace other metals in their complexes and it does not produce hydroxyl radicals like iron [4,53]. This and other possible ColRS-independent manganese tolerance mechanisms could be the reasons why inactivation of ColRS signaling does not result in 
major effects in the manganese tolerance of $P$. putida. Intriguingly, cadmium promoted the strongest activation of the ColR regulon genes but, despite that, the cadmium tolerance of colRS mutants was hardly affected, being observable only in liquid and not in solid medium (Figure 1, Table 1). This suggests that the ColRS system is of little importance under cadmium stress and other resistance mechanisms exist that confer the cadmium tolerance of P. putida. The most probable candidates could be the several cadmium-induced efflux systems which are known to contribute to cadmium resistance of $P$. putida [54]. Given all these data, we suggest that although manganese and cadmium can activate the ColRS signaling, the primary role of ColRS is to maintain zinc and iron homeostasis.

The metal-controlled ColR regulon includes genes and operons putatively involved in the synthesis and/or modification of LPS or in the metabolism of phospholipides (Figure 2, Table 2). Notably, deletion of most of the ColR regulon genes individually did not change the metal sensitivity of bacteria and inactivation of at least four loci was necessary to observe their effect on metal tolerance. The only locus that could significantly contribute to zinc, but not iron tolerance, is the PP0035PP0033 operon that codes for three membrane proteins. This operon is most probably involved in LPS modification because PP0033 and PP0034 code for proteins homologous to ArnT (referred also as PmrK or PbgE) and ArnC, respectively, which decorate lipid A with the cationic sugar 4-amino-4-deoxy-L-arabinose [55,56]. The addition of 4-amino-4-deoxy-L-arabinose to lipid A decreases the negative charge of LPS, which has been demonstrated to increase the resistance of Salmonella to cationic antimicrobial peptides and also to $\mathrm{Fe}^{3+}$ and $\mathrm{Al}^{3+}$ $[17,18]$. Analogously, we consider that the impact of PP0033 and PP0034 in metal tolerance may rely on their ability to modify LPS. Notably, there is another gene in the ColR regulon, which can putatively decrease the negative charge of cell surface by LPS modification. The ColR-activated PP2579 encodes a protein homologous to CptA phosphotransferase, which catalyzes the phosphoethanolamine addition to the LPS core [57]. Interestingly, genes responsible for the addition of 4amino-4-deoxy-L-arabinose and phosphoethanolamine to LPS in Salmonella are regulated by the PmrAB twocomponent system [57-59], which, like ColRS, responds to external iron [16]. This suggests that the mechanism how ColRS system impacts the metal tolerance of $P$. putida partly resembles that of $\mathrm{PmrAB}$, where modification of LPS plays a major role in protecting bacteria from metal toxicity $[18,60,61]$. However, we want to emphasize that the effect of PP0035-PP0033 and PP2579 in metal tolerance is rather low and that the ColR-controlled metal tolerance is actually provided by the joint action of the whole regulon.
Several signaling systems which regulate bacterial response to external metals are induced by the same environmental cue they respond to. For example, expression of pmrAB in Salmonella is induced by iron, basSR in E. coli is induced by iron and zinc, bqsRS and $c z c R S$ in $P$. aeruginosa are upregulated by iron and cadmium, respectively $[16,26,45,46]$. Differently from these systems, the expression of colRS is not affected by metals and the ColRS-promoted response to metal excess only involves activation of the signal transduction between the system counterparts and the resulting changes in the expression of the ColR regulon genes. This suggests that the basal constitutive expression level of the colRS operon is sufficient to guarantee an appropriate response to metal stress.

Mutational analysis of ColS indicates that a conserved ExxE motif of the periplasmic loop of the sensor kinase is required for sensing both iron and zinc, because substitution of either of the conserved glutamic acid residues in this motif abolishes the ability of ColS to respond to both metals and to promote the activation of the ColR regulon (Figure 6). The ExxE motif has been demonstrated to bind iron in several eukaryotic and prokaryotic proteins, including, for instance, the iron transporter FTR1 in Saccharomyces cerevisiae [48], the iron sensor PmrA in Salmonella enterica [16], the iron- and heme-binding HbpS in Streptomyces reticuli [49]. Interestingly, as far as we know, there are no previous reports demonstrating that the iron-binding ExxE motif could also bind zinc. However, given that glutamates have been found to coordinate the zinc ion in many zinc-binding proteins [62], the zinc-binding ability of the ExxE motif is actually anticipated and one may suspect that other ExxE motif-containing proteins could bind zinc as well. Mutational analysis of ColS also showed that while the ExxE motif is necessary for iron and zinc sensing, the other conserved amino acids in the ColS periplasmic domain are important for the regulation of the signaling ability of ColS. Besides, it is remarkable that none of the amino acid substitutions outside the ExxE motif decreased the signaling ability of ColS and some even increased it. For example, the substitutions H35A, E38Q, D57N and H105A significantly increased the responsiveness of ColS to both iron and zinc (Figure 6), suggesting that these positions are important for keeping ColS in the inactive state and for preventing premature signaling under non-induced conditions. Notably, the mutations E38Q, D57N and H105A resulted in somewhat higher signaling of ColS even without metal stress, implying that the conformations of the $\mathrm{ColS}_{\mathrm{E} 38 \mathrm{Q}}, \mathrm{ColS}_{\mathrm{D} 57 \mathrm{~N}}$ and $\mathrm{ColS}_{\mathrm{H} 105 \mathrm{~A}}$ are changed, allowing the higher basal kinase activity of the proteins. Interestingly, another clue suggests that the ColS region containing H105 is important for regulation of ColS activity by keeping the sensor in 
the inactive form. Recently, the ColRS system was shown to support the polymyxin resistance of $P$. aeruginosa, whereas the mutant ColS possessing a substitution A106V seemed to enhance the polymyxin resistance of a $P$. aeruginosa clinical isolate [63]. It is tempting to speculate that the $\mathrm{ColS}_{\mathrm{A} 106 \mathrm{~V}}$ in $P$. aeruginosa, analogously to our Col$\mathrm{S}_{\mathrm{H} 105 \mathrm{~A}}$, may also be more active than wild-type ColS, resulting in higher activation of the ColR regulon and, as a consequence, higher polymyxin resistance of $P$. aeruginosa.

It has been shown that four glutamic acids of two ExxE motifs located in different monomers participate in coordinating of iron in the octameric HbpS [49]. Given that the zinc ion also has a marked preference for tetrahedral coordination geometry [62], two ExxE motifs should be involved in binding of zinc as well. As ColS possesses only one conserved ExxE motif in its periplasmic domain, we propose a model involving dimeric ColS, where, analogous to $\mathrm{HbpS}$, each monomer donates one ExxE motif for metal binding (Figure 8). The ExxE motif of ColS is located in the most C-terminal part of the periplasmic domain, positioned close to the second transmembrane domain. Therefore, it is most probable that the two ExxE motifs are located closely in the ColS dimer and are oriented towards each other in the interface of adjacent subunits (Figure 8). If the extracellular concentration of $\mathrm{Fe}^{3+}$ or $\mathrm{Zn}^{2+}$ exceeds a certain threshold level, the ColS dimer will bind the metal ion, resulting most probably in a conformational change and autophosphorylation of ColS. Subsequent signal transduction to ColR and activation of the ColR regulon leads to modifications in the cell membrane, which helps bacteria cope with metal excess. Considering that the metal-sensing ExxE motif of ColS is highly conserved in all sequenced pseudomonads, it suggests that the other ColRS systems may have a similar metal-sensing mechanism as well.

\section{Conclusion}

The most important result of the current study is that for the first time, the signal for a ColRS two-component system has been determined. We show that ColS is a metal sensor which is activated when the growth medium contains excess iron, zinc, manganese or cadmium. Our data indicate that a conserved ExxE motif in the periplasmic domain of ColS is involved in both zinc and iron sensing and is able to distinguish between different iron ions, responding only to ferric iron. The finding that the ExxE motif is involved in zinc sensing is novel as it has previously been reported to bind iron only $[16,48,49]$. We show that the metal-promoted activation of ColS results in the activation of the ColR regulon which is necessary to protect the bacteria from metal-mediated toxicity. This adaptive system could be highly beneficial for soil bacteria,

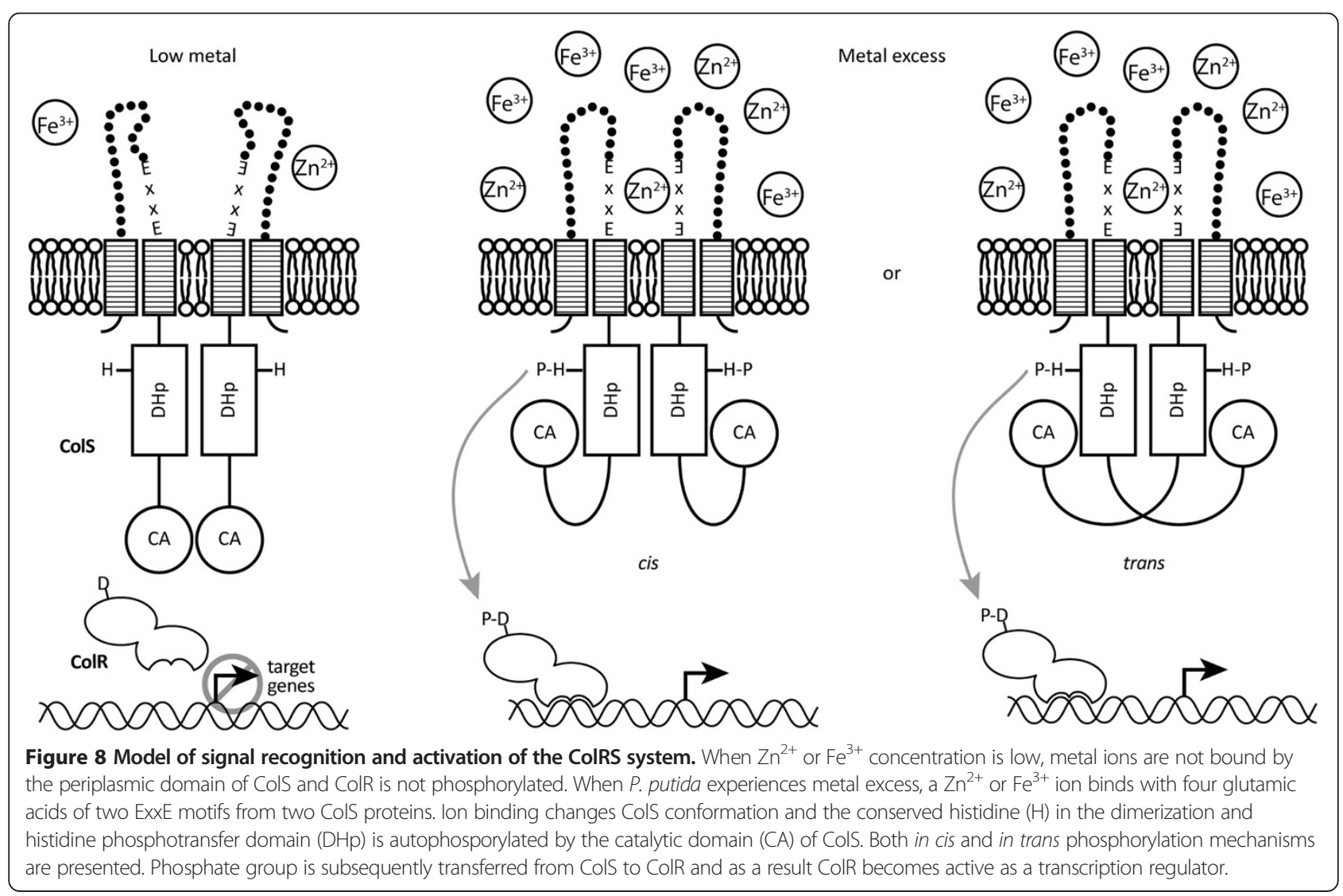


such as P. putida and other pseudomonads, as well as Xanthomonas species, as they may experience elevated metal concentrations in their native environments.

\section{Methods}

\section{Bacterial strains, plasmids, and media}

The bacterial strains and plasmids used are listed in Additional file 1 . All $P$. putida strains are derivatives of PaW85 [64], which is isogenic to the fully sequenced KT2440 [65]. Bacteria were grown in lysogeny broth (LB). To generate metal stress, the LB medium was supplemented with the following metal salts: $\mathrm{ZnSO}_{4}, \mathrm{FeSO}_{4}$, $\mathrm{Fe}_{2}\left(\mathrm{SO}_{4}\right)_{3}, \mathrm{CuSO}_{4}, \mathrm{NiSO}_{4}, \mathrm{CdSO}_{4}, \mathrm{MnCl}_{2}$, and $\mathrm{CoCl}_{2}$. When selection was necessary, the growth medium was supplemented with ampicillin $\left(100 \mu \mathrm{g} \mathrm{ml}^{-1}\right)$, kanamycin $\left(50 \mu \mathrm{g} \mathrm{ml}^{-1}\right)$ or streptomycin $\left(20 \mu \mathrm{g} \mathrm{ml}^{-1}\right)$ for E. coli and benzylpenicillin $\left(800 \mu \mathrm{g} \mathrm{ml}^{-1}\right)$, kanamycin $\left(50 \mu \mathrm{g} \mathrm{ml}^{-1}\right)$ or streptomycin $\left(100 \mu \mathrm{g} \mathrm{ml}^{-1}\right)$ for P. putida. E. coli was incubated at $37^{\circ} \mathrm{C}$ and $P$. putida at $30^{\circ} \mathrm{C}$. Bacteria were electrotransformed according to the protocol of Sharma and Schimke [66].

\section{Construction of plasmids and strains}

Oligonucleotides used in PCR amplifications are listed in Additional file 2. For complementation of the colsdeficient strain with an IPTG-inducible copy of colS, the cols gene was first amplified from the P. putida PaW85 chromosome with primers ColSSal and ColSHincII. The PCR fragment was cut with SalI and HincII and cloned into SalI-SmaI-opened pBRlacItac. The $\operatorname{lacl}^{q}-P_{t a c}-c o l S$ cassette was excised from the plasmid pBRlacItac/colS with BamHI and Acc65I, and ligated into the corresponding sites of the plasmid pUC18Not to obtain pUCNot/lacitaccolS. Finally, the colS expression cassette was subcloned as a NotI fragment into the miniTn7 delivery plasmid pBK-miniTn7- $\Omega \mathrm{Sm}$. For the construction Col$\mathrm{S}_{\mathrm{H} 35 \mathrm{~A}}, \mathrm{ColS}_{\mathrm{E} 38 \mathrm{Q}}, \mathrm{ColS}_{\mathrm{D} 57 \mathrm{~N}}, \mathrm{ColS}_{\mathrm{H} 95 \mathrm{~A}}, \mathrm{ColS}_{\mathrm{E} 96 \mathrm{Q}}, \mathrm{ColS}_{\mathrm{H} 105 \mathrm{~A}}$, $\mathrm{ColS}_{\mathrm{E} 126 \mathrm{Q}}, \mathrm{ColS}_{\mathrm{E} 129 \mathrm{Q}}$ and $\mathrm{ColS}_{\mathrm{E} 126 \mathrm{Q} / \mathrm{E} 129 \mathrm{Q}}$ expression cassettes, the site-directed mutagenesis of wild-type colS was performed using two sequential PCRs and the plasmid pUCNot/lacitaccolS as a template. In the first PCR, one primer carried the substitution mutation and the other was either Smut1 or Smut2 (see Additional file 3). The product of the first PCR served as a reverse primer for Smut1 or Smut2 in the second PCR. The product of the second PCR was treated with DpnI, Mva1269I and Bpu1102I, and ligated into the Mva1269I-Bpu1102I-opened pUCNot/ lacitaccolS. After verification of designed mutations by sequencing, the expression cassettes with the mutated cols gene were subcloned into the NotI site in plasmid pBK-miniTn7- $\Omega S m$. The pBK-miniTn7- $\Omega$ Sm derivatives, bearing either wild-type or mutant colS expression cassette, were introduced into P. putida colS-deficient strain by co-electroporation together with the helper plasmid
pUXBF13. Presence of the expression cassette in the attTn7 site of the colS-deficient strain was verified by PCR.

For construction of $P$. putida derivatives devoid of PP0268, PP0900, PP1636 or PP5152, the loci were disrupted with the streptomycin resistance gene. PP0268, PP0900, PP1636 or PP5152 were amplified with primer pairs oprE3Bam + oprE3Xho, 900Kpn + colRATGXho, PP1635lopp + PP1636Kpn and 5152lopp + 5153lopp, respectively. PP0268-containing PCR fragment was treated with BamHI (blunt-ended with Klenow DNA polymerase) and XhoI and cloned into pBluescript KS. The central 700bp region of PP0268 in pKS/268 was excised with HincII and Eco47III and replaced with the $\mathrm{Sm}^{\mathrm{r}}$ gene cut from pUTmini-Tn5Sm/Sp with VspI. The obtained 268::Sm sequence was subcloned as an EcoRI-Acc65I fragment into pGP704L. PP0900-containing PCR fragment was treated with Eco147I and Acc65I and cloned into the SmaI-Acc65I-opened pBluescript KS. Next, the central 87-bp EheI-Eco130I sequence in pKS/900 was replaced with the $\mathrm{Sm}^{\mathrm{r}}$ gene and the resulting 900::Sm sequence was subcloned into pGP704L using SacI and Acc65I. The PP1636-containing PCR fragment was cloned into pBluescript KS as a HindIII-Acc65I fragment. The central 143-bp Mva1269I-ClaI region of PP1636 in pKS/ 1636 was replaced with the $\mathrm{Sm}^{\mathrm{r}}$ gene and the $1636:: \mathrm{Sm}$ sequence was inserted into pGP704L using SacI and Acc65I. The PP5152-containing PCR fragment was cloned into pBluescript KS as a PstI-Acc65I fragment. The central 377-bp HincII-Bpu1102I fragment of PP5152 in pKS/5152 was replaced with the $\mathrm{Sm}^{\mathrm{r}}$ gene and the $5152:: \mathrm{Sm}$ sequence was inserted into pGP704L using XbaI and PvuII. The interrupted PP0268, PP0900, PP1636 or PP5152 genes were inserted into the chromosome of P. putida PaW85 and its knockout derivatives by homologous recombination. Plasmids p704L/268::Sm, p704L/ 900::Sm, p704L/1636::Sm or p704L/5152::Sm were conjugatively transferred from $E$. coli CC118 $\lambda$ pir into $P$. putida using the helper plasmid pRK2013. The gene knockout strains were verified by PCR analysis.

For generation of deletion strains devoid of single or multiple genes, the pEMG-based plasmids were constructed according to the protocol described elsewhere [67]. The upstream and downstream regions (about $500 \mathrm{bp}$ ) of the gene(s) to be deleted were amplified separately and then joined into one fragment by overlap extension PCR. For construction of the plasmids pEMG- $\Delta 35-33$, pEMG- $\Delta 737$, pEMG- $\Delta 903-905$ and pEMG- $\Delta 2579$, the PCR fragments of about $1 \mathrm{~kb}$ were cut with SalI and EcoRI, BamHI and EcoRI, Acc65I and SacI, and SalI and SacI, respectively, and ligated into the corresponding sites of the plasmid pEMG. The obtained pEMG plasmids were delivered to $P$. putida PaW85 or its knockout derivative strains by electroporation and after 3 hours of growth in LB medium the bacteria 
were plated onto LB agar supplemented with kanamycin. Kanamycin-resistant co-integrates were selected and electrotransformed with the I-SceI expression plasmid $\mathrm{pSW}(\mathrm{I}-\mathrm{SceI})$. In order to resolve the cointegrate, the plasmid-encoded I-SceI was induced with $1.5 \mathrm{mM}$ 3-methylbenzoate overnight. Kanamycin-sensitive colonies were selected and the deletions of PP0035-PP0033, PP0737, PP0903-PP0905 or PP2579 were verified by PCR. The plasmid pSW(I-SceI) was eliminated from the deletion strains by growing them overnight in LB medium without antibiotics.

To construct the transcriptional fusions of the PP2579 and PP5152 promoters with $l a c Z$, the upstream regions of PP2579 and PP5152 were amplified from the P. putida PaW85 chromosome with primers PP2579alg and PP2580alg, and 5152alg and 5153lopp, respectively. The resulting PCR fragments were treated with HindIII and inserted into HindIII-opened $\mathrm{p} 9 \mathrm{TT}_{\mathrm{B}}$ lacZ.

\section{Metal tolerance plate assay}

Metal tolerance was evaluated on LB agar plates containing different concentrations of metal salts (concentrations are specified in Results). The LB-grown overnight cultures were tenfold serially diluted, spotted onto plates as $5 \mu \mathrm{l}$ drops and incubated at $30^{\circ} \mathrm{C}$ for 20 hours.

\section{Determination of minimal inhibitory concentrations (MICs) of metals}

The MICs of different metals were determined for bacteria growing in microtiter plates. The microtiter plate wells containing serial dilutions of metal salts in $100 \mu \mathrm{l}$ LB medium were inoculated with about $1 \times 10^{6}$ cells of bacterial culture pre-grown overnight in LB medium. Microtiter plates were incubated with shaking at $30^{\circ} \mathrm{C}$ for $24 \mathrm{~h}$, after which the $\mathrm{OD}_{580}$ was measured. The MIC was defined as the lowest concentration of metal that allowed no bacterial growth. For each metal and bacterial strain, at least three independent experiments were carried out.

\section{$\beta$-galactosidase assay}

Enzyme activities were measured from bacteria grown overnight in LB or in LB supplemented with different metal salts (concentrations are specified in Results). $\beta$-galactosidase activity was assayed according to a previously described protocol [68].

\section{Western blotting}

Cell lysates were prepared from bacteria grown overnight in $\mathrm{LB}$ or in $\mathrm{LB}$ supplemented with either $0.6 \mathrm{mM} \mathrm{ZnSO}_{4}$ or $0.15 \mathrm{mM} \mathrm{FeSO}_{4}$. Equal amounts of total protein $(3 \mu \mathrm{g})$ were separated by Tricine-SDS-PA gel electrophoresis, followed by protein transfer to a nitrocellulose membrane. For Western blotting, the membranes were probed with
ColR-specific polyclonal antibodies, followed by treatment with alkaline phosphatase-conjugated goat antirabbit immunoglobulin G. The blots were developed using bromochloroindolyl phosphate/nitro blue tetrazolium (BCIP/NBT).

\section{Additional files}

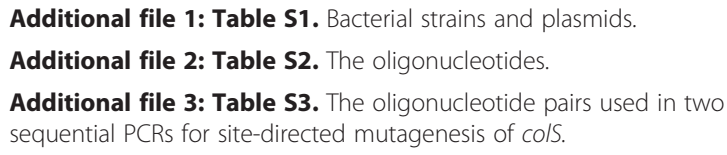

\section{Competing interests}

The authors declare that they have no competing interests.

\section{Author's contributions}

KA carried out all enzyme activity measurements, performed Cols mutagenesis and tolerance plate assays. KM performed MIC measurements. KA, RH and $\mathrm{HI}$ constructed the plasmids and strains. $\mathrm{RH}$ conceived, designed and coordinated experimental work and manuscript editing. All authors read and approved the final manuscript.

\section{Acknowledgments}

We are grateful to Hedvig Tamman, Andres Ainelo and Hanna Hõrak for critically reading the manuscript. We thank Külliki Holtsmann for assistance in the cloning and Peeter Horrak and Riho Teras for advice in the statistical analysis. This work was supported by the grant 7829 from the Estonian Science Foundation, by Targeted Financing Project TLOMR0031 and by Institutional Research grant IUT20-19.

Received: 14 February 2014 Accepted: 17 June 2014

Published: 20 June 2014

\section{References}

1. Andreini C, Bertini I, Cavallaro G, Holliday GL, Thornton JM: Metal ions in biological catalysis: from enzyme databases to general principles. J Biol Inorg Chem 2008, 13(8):1205-1218.

2. Touati D: Iron and oxidative stress in bacteria. Arch Biochem Biophys 2000, 373(1):1-6.

3. Imlay JA: Iron-sulphur clusters and the problem with oxygen. $\mathrm{Mol}$ Microbiol 2006, 59(4):1073-1082

4. McDevitt CA, Ogunniyi AD, Valkov E, Lawrence MC, Kobe B, McEwan AG, Paton JC: A molecular mechanism for bacterial susceptibility to zinc. PLOS Pathog 2011, 7(11):e1002357.

5. Outten CE, O'Halloran TV: Femtomolar sensitivity of metalloregulatory proteins controlling zinc homeostasis. Science 2001, 292(5526):2488-2492

6. Changela A, Chen K, Xue Y, Holschen J, Outten CE, O'Halloran TV, Mondragon A: Molecular basis of metal-ion selectivity and zeptomolar sensitivity by CueR. Science 2003, 301(5638):1383-1387.

7. Nies DH: Efflux-mediated heavy metal resistance in prokaryotes. FEMS Microbiol Rev 2003, 27(2-3):313-339.

8. Brocklehurst KR, Hobman JL, Lawley B, Blank L, Marshall SJ, Brown NL, Morby AP: ZntR is a $\mathrm{Zn}$ (II)-responsive MerR-like transcriptional regulator of zntA in Escherichia coli. Mol Microbiol 1999, 31(3):893-902.

9. Outten FW, Outten CE, Hale J, O'Halloran TV: Transcriptional activation of an Escherichia coli copper efflux regulon by the chromosomal MerR homologue, cueR. J Biol Chem 2000, 275(40):31024-31029.

10. Blindauer CA, Harrison MD, Parkinson JA, Robinson AK, Cavet JS, Robinson NJ, Sadler PJ: A metallothionein containing a zinc finger within a four-metal cluster protects a bacterium from zinc toxicity. Proc Natl Acad Sci U S A 2001, 98(17):9593-9598.

11. Pulliainen AT, Kauko A, Haataja S, Papageorgiou AC, Finne J: Dps/Dpr ferritin-like protein: insights into the mechanism of iron incorporation and evidence for a central role in cellular iron homeostasis in Streptococcus suis. Mol Microbiol 2005, 57(4):1086-1100. 
12. Hantke K: Bacterial zinc uptake and regulators. Curr Opin Microbio/ 2005, 8(2):196-202.

13. Moore CM, Helmann JD: Metal ion homeostasis in Bacillus subtilis. Curr Opin Microbiol 2005, 8(2):188-195.

14. Carpenter BM, Whitmire JM, Merrell DS: This is not your mother's repressor: the complex role of fur in pathogenesis. Infect Immun 2009, 77(7):2590-2601.

15. Horsburgh MJ, Ingham E, Foster SJ: In Staphylococcus aureus, Fur is an interactive regulator with PerR, contributes to virulence, and Is necessary for oxidative stress resistance through positive regulation of catalase and iron homeostasis. J Bacteriol 2001, 183(2):468-475.

16. Wösten MM, Kox LF, Chamnongpol S, Soncini FC, Groisman EA: A signal transduction system that responds to extracellular iron. Cell 2000, 103(1):113-125.

17. Gunn JS: The Salmonella PmrAB regulon: lipopolysaccharide modifications, antimicrobial peptide resistance and more. Trends Microbio/ 2008, 16(6):284-290.

18. Nishino K, Hsu FF, Turk J, Cromie MJ, Wosten MM, Groisman EA: Identification of the lipopolysaccharide modifications controlled by the Salmonella PmrA/ PmrB system mediating resistance to $\mathrm{Fe}$ (III) and $\mathrm{Al}(\mathrm{III})$. Mol Microbio/ 2006, 61(3):645-654.

19. Kato A, Chen HD, Latifi T, Groisman EA: Reciprocal control between a bacterium's regulatory system and the modification status of its lipopolysaccharide. Mol Cell 2012, 47(6):897-908

20. Ogasawara H, Shinohara S, Yamamoto K, Ishihama A: Novel regulation targets of the metal-response BasS-BasR two-component system of Escherichia coli. Microbiology 2012, 158(Pt 6):1482-1492.

21. Leonhartsberger S, Huber A, Lottspeich F, Bock A: The hydH/G Genes from Escherichia coli code for a zinc and lead responsive two-component regulatory system. J Mol Biol 2001, 307(1):93-105.

22. Appia-Ayme C, Hall A, Patrick E, Rajadurai S, Clarke TA, Rowley G: ZraP is a periplasmic molecular chaperone and a repressor of the zinc-responsive two-component regulator ZraSR. Biochem J 2012, 442(1):85-93.

23. Timmis KN: Pseudomonas putida: a cosmopolitan opportunist par excellence. Environ Microbiol 2002, 4(12):779-781.

24. Strateva T, Yordanov D: Pseudomonas aeruginosa - a phenomenon of bacterial resistance. J Med Microbiol 2009, 58(Pt 9):1133-1148.

25. Dos Santos VA, Heim S, Moore ER, Stratz M, Timmis KN: Insights into the genomic basis of niche specificity of Pseudomonas putida KT2440. Environ Microbiol 2004, 6(12):1264-1286.

26. Perron K, Caille O, Rossier C, Van Delden C, Dumas JL, Kohler T: CzcR-CzcS, a two-component system involved in heavy metal and carbapenem resistance in Pseudomonas aeruginosa. J Biol Chem 2004, 279(10):8761-8768.

27. Teitzel GM, Geddie A, De Long SK, Kirisits MJ, Whiteley M, Parsek MR: Survival and growth in the presence of elevated copper: transcriptional profiling of copper-stressed Pseudomonas aeruginosa. J Bacteriol 2006, 188(20):7242-7256.

28. Caille O, Rossier C, Perron K: A copper-activated two-component system interacts with zinc and imipenem resistance in Pseudomonas aeruginosa. J Bacteriol 2007, 189(13):4561-4568.

29. Zhang XX, Rainey PB: Regulation of copper homeostasis in Pseudomonas fluorescens SBW25. Environ Microbiol 2008, 10(12):3284-3294.

30. Moskowitz SM, Ernst RK, Miller SI: PmrAB, a two-component regulatory system of Pseudomonas aeruginosa that modulates resistance to cationic antimicrobial peptides and addition of aminoarabinose to lipid $A$. J Bacteriol 2004, 186(2):575-579.

31. Winsor GL, Van Rossum T, Lo R, Khaira B, Whiteside MD, Hancock RE, Brinkman FS: Pseudomonas Genome Database: facilitating user-friendly, comprehensive comparisons of microbial genomes. Nucleic Acids Res 2009, 37:D483-D488.

32. Dekkers LC, Bloemendaal CJ, de Weger LA, Wijffelman CA, Spaink HP, Lugtenberg BJ: A two-component system plays an important role in the root-colonizing ability of Pseudomonas fluorescens strain WCS365. Mol Plant Microbe Interact 1998, 11(1):45-56.

33. Garvis S, Munder A, Ball G, de Bentzmann S, Wiehlmann L, Ewbank JJ, Tümmler B, Filloux A: Caenorhabditis elegans semi-automated liquid screen reveals a specialized role for the chemotaxis gene cheB2 in Pseudomonas aeruginosa virulence. PLoS Pathog 2009, 5(8):e1000540.

34. Yan $\mathrm{Q}$, Wang N: The ColR/ColS two-component system plays multiple roles in the pathogenicity of the citrus canker pathogen Xanthomonas citri subsp. citri. J Bacteriol 2011, 193(7):1590-1599.
35. Subramoni S, Pandey A, Vishnupriya MR, Patel HK, Sonti RV: The ColRS system of Xanthomonas oryzae pv. oryzae is required for virulence and growth in iron-limiting conditions. Mol Plant Pathol 2012, 13(7):690-703.

36. Kivistik PA, Putrinš M, Püvi K, Ilves H, Kivisaar M, Hõrak R: The ColRS twocomponent system regulates membrane functions and protects Pseudomonas putida against phenol. J Bacteriol 2006, 188(23):8109-8117.

37. Putrinš M, Ilves H, Lilje L, Kivisaar M, Hõrak R: The impact of ColRS twocomponent system and $\operatorname{Ttg} A B C$ efflux pump on phenol tolerance of Pseudomonas putida becomes evident only in growing bacteria. BMC Microbiol 2010, 10:110

38. Putrinš M, Ainelo A, Ilves H, Hõrak R: The ColRS system is essential for the hunger response of glucose-growing Pseudomonas putida. BMC Microbiol 2011, 11:170.

39. Putrinš M, Ilves H, Kivisaar M, Hõrak R: ColRS two-component system prevents lysis of subpopulation of glucose-grown Pseudomonas putida. Environ Microbiol 2008, 10(10):2886-2893.

40. Kivistik PA, Kivi R, Kivisaar M, Hõrak R: Identification of ColR binding consensus and prediction of regulon of ColRS two-component system. BMC Mol Biol 2009, 10:46.

41. de Weert S, Dekkers LC, Bitter W, Tuinman S, Wijfjes AH, van Boxtel R, Lugtenberg BJ: The two-component colR/S system of Pseudomonas fluorescens WCS365 plays a role in rhizosphere competence through maintaining the structure and function of the outer membrane. FEMS Microbiol Ecol 2006, 58(2):205-213.

42. Zhang SS, He YQ, Xu LM, Chen BW, Jiang BL, Liao J, Cao JR, Liu D, Huang YQ, Liang XX, Tang TJ, Lu GT, Tang JL: A putative colR(XC1049)-colS (XC1050) two-component signal transduction system in Xanthomonas campestris positively regulates $h r p C$ and $h r p E$ operons and is involved in virulence, the hypersensitive response and tolerance to various stresses. Res Microbiol 2008, 159(7-8):569-578.

43. Hu N, Zhao B: Key genes involved in heavy-metal resistance in Pseudomonas putida CD2. FEMS Microbiol Lett 2007, 267(1):17-22.

44. Hõrak R, Ilves H, Pruunsild P, Kuljus M, Kivisaar M: The ColR-ColS twocomponent signal transduction system is involved in regulation of Tn4652 transposition in Pseudomonas putida under starvation conditions. Mol Microbiol 2004, 54(3):795-807.

45. Lee $\sqcup$, Barrett JA, Poole RK: Genome-wide transcriptional response of chemostat-cultured Escherichia coli to zinc. J Bacterio/ 2005, 187(3):1124-1134.

46. Kreamer NN, Wilks JC, Marlow JJ, Coleman ML, Newman DK: BqsR/BqsS constitute a two-component system that senses extracellular $\mathrm{Fe}(\mathrm{II})$ in Pseudomonas aeruginosa. J Bacteriol 2012, 194(5):1195-1204.

47. Ma Z, Jacobsen FE, Giedroc DP: Coordination chemistry of bacterial metal transport and sensing. Chem Rev 2009, 109(10):4644-4681.

48. Stearman R, Yuan DS, Yamaguchi-Iwai Y, Klausner RD, Dancis A: A permease-oxidase complex involved in high-affinity iron uptake in yeast. Science 1996, 271(5255):1552-1557.

49. Wedderhoff I, Kursula I, Groves MR, Ortiz de Orue Lucana D: Iron binding at specific sites within the octameric $\mathrm{HbpS}$ protects Streptomycetes from iron-mediated oxidative stress. PLoS One 2013, 8(8):e71579.

50. Baker KR, Postle K: Mutations in Escherichia coli ExbB transmembrane domains identify scaffolding and signal transduction functions and exclude participation in a proton pathway. J Bacterio/ 2013, 195(12):2898-2911.

51. Wen J, Chen X, Bowie JU: Exploring the allowed sequence space of a membrane protein. Nat Struct Biol 1996, 3(2):141-148.

52. Steele $\mathrm{KH}, \mathrm{O}^{\prime}$ Connor $\mathrm{LH}$, Burpo N, Kohler K, Johnston JW: Characterization of a ferrous iron-responsive two-component system in nontypeable Haemophilus influenzae. J Bacterio/ 2012, 194(22):6162-6173.

53. Aguirre JD, Culotta VC: Battles with iron: manganese in oxidative stress protection. J Biol Chem 2012, 287(17):13541-13548.

54. Leedjärv A, Ivask A, Virta M: Interplay of different transporters in the mediation of divalent heavy metal resistance in Pseudomonas putida KT2440. J Bacteriol 2008, 190(8):2680-2689.

55. Trent MS, Ribeiro AA, Lin S, Cotter R, Raetz CR: An inner membrane enzyme in Salmonella and Escherichia coli that transfers 4-amino-4-deoxy-L-arabinose to lipid A: induction on polymyxin-resistant mutants and role of a novel lipid-linked donor. J Biol Chem 2001, 276(46):43122-43131.

56. Breazeale SD, Ribeiro AA, McClerren AL, Raetz CR: A formyltransferase required for polymyxin resistance in Escherichia coli and the modification of lipid A with 4-Amino-4-deoxy-L-arabinose. Identification and function oF UDP-4-deoxy-4-formamido-L-arabinose. J Biol Chem 2005, 280(14):14154-14167. 
57. Tamayo R, Choudhury B, Septer A, Merighi M, Carlson R, Gunn JS: Identification of $c p t A$, a PmrA-regulated locus required for phosphoethanolamine modification of the Salmonella enterica serovar typhimurium lipopolysaccharide core. J Bacteriol 2005, 187(10):3391-3399.

58. Gunn JS, Lim KB, Krueger J, Kim K, Guo L, Hackett M, Miller SI: PmrA-PmrBregulated genes necessary for 4 -aminoarabinose lipid $A$ modification and polymyxin resistance. Mol Microbiol 1998, 27(6):1171-1182.

59. Wösten MM, Groisman EA: Molecular characterization of the PmrA regulon. J Biol Chem 1999, 274(38):27185-27190.

60. Chamnongpol S, Dodson W, Cromie MJ, Harris ZL, Groisman EA: Fe(III)mediated cellular toxicity. Mol Microbiol 2002, 45(3):711-719.

61. Chen HD, Groisman EA: The biology of the PmrA/PmrB two-component system: the major regulator of lipopolysaccharide modifications. Annu Rev Microbiol 2013, 67:83-112.

62. Laitaoja M, Valjakka J, Janis J: Zinc coordination spheres in protein structures. Inorg Chem 2013, 52(19):10983-10991.

63. Gutu AD, Sgambati N, Strasbourger P, Brannon MK, Jacobs MA, Haugen E, Kaul RK, Johansen HK, Hoiby N, Moskowitz SM: Polymyxin resistance of Pseudomonas phoQ mutants is dependent on additional two-component regulatory systems. Antimicrob Agents Chemother 2013, 57(5):2204-2215.

64. Bayley SA, Duggleby CJ, Worsey MJ, Williams PA, Hardy KG, Broda P: Two modes of loss of the Tol function from Pseudomonas putida mt-2. Mol Gen Genet 1977, 154(2):203-204.

65. Regenhardt D, Heuer H, Heim S, Fernandez DU, Strömpl C, Moore ER, Timmis KN: Pedigree and taxonomic credentials of Pseudomonas putida strain KT2440. Environ Microbiol 2002, 4(12):912-915.

66. Sharma RC, Schimke RT: Preparation of electrocompetent E. coli using salt-free growth medium. Biotechniques 1996, 20(1):42-44.

67. Martinez-Garcia E, de Lorenzo V: Engineering multiple genomic deletions in Gram-negative bacteria: analysis of the multi-resistant antibiotic profile of Pseudomonas putida KT2440. Environ Microbiol 2011, 13(10):2702-2716.

68. Miller JH: A short course in bacterial genetics: a laboratory manual and handbook for Echerichia coli and related bacteria. Cold Spring Harbour, NY: Cold Spring Harbour Laboratory Press; 1992.

doi:10.1186/1471-2180-14-162

Cite this article as: Ainsaar et al:: The ColRS signal transduction system responds to the excess of external zinc, iron, manganese, and cadmium. BMC Microbiology 2014 14:162.

\section{Submit your next manuscript to BioMed Central and take full advantage of:}

- Convenient online submission

- Thorough peer review

- No space constraints or color figure charges

- Immediate publication on acceptance

- Inclusion in PubMed, CAS, Scopus and Google Scholar

- Research which is freely available for redistribution 